\title{
Dynamic Simulation of Rigid Guide Structure Based on ANSYS
}

\author{
ZHANG Xin ${ }^{1, a}$ and WANG Zhe ${ }^{2}$ \\ ${ }^{1}$ Anhui University of Science and Technology, Huainan Anhui, China \\ ${ }^{2}$ Anhui University of Science and Technology, Huainan Anhui, China
}

\begin{abstract}
In order to reflect the varying law of the deflection of the rigid guide when the relative motion occur between the rigid guide and the cage roller, transient dynamic simulation is carried out for the commonly used calculation model of rigid guide and bunton by ANSYS. Simulation of the horizontal force through a section of the guide evenly, and the deflection curves of each model are obtained. It is found that the deflection of the simply supported beam model is the largest, and the three-span continuous beam model have similar peak spans in each span with the spatial grid model, but the spatial grid model has obvious fluctuation with the horizontal force.
\end{abstract}

\section{Introduction}

Rigid guide is an important part of shaft equipment. At present, the simple beam model and the threespan continuous beam model is still widely used in the calculation of bending resistance of the guide, and the influence of the space structure composed of guide and bunton is not taken into account. The bending moment of the force point is too large, so that the design value tends to be conservative [1]. But the research on the difference of deflection of each model under the action of the moving load is still blank.

In this paper, the transient dynamic simulation of these three models under the action of the moving load is carried out by ANSYS to get the deflection changes in the midpoint. Then export the data to MATLAB, so the curves of the variation of deflection in each span about the simple beam model, three-span equal-span continuous beam model and spatial grid model under the moving load are presented. It has a certain guiding significance for the structural design calculation of rigid guide and bunton.

\section{Calculation Model of Rigid Guide and Bunton}

The dynamic load transmitted by the hoisting conveyance be resisted by rigid guide and bunton in the hoisting process, the guide structure has an important impact on the safety and reliability of the hoisting conveyance[2]. The design and calculation of guide now, the majority consider static function at one point. However, in most of the hoisting process the role of the horizontal force is not stage but continuous, so considering the load through the rigid guide at a uniform speed, a variety of rigid guide

${ }^{a}$ ZHANG Xin : xzhang@aust.edu.cn 
deflection curve calculation model is necessary. In the stage of uniform hoisting of the hoisting conveyance, it is assumed that the transverse horizontal force acting on the guide by the cage roller does not change, so the simply supported beam model, three-span continuous beam model and spatial grid model can be built in Figure 1. The force of the cage roller on the guide is simplified as a force perpendicular to the beam, the relative motion of the cage roller and the guide into a uniform translation is simplified as a force along the axis of the beam.

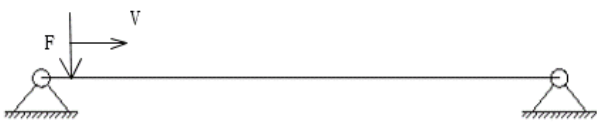

A simply supported beam model

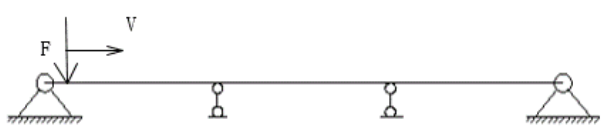

B three-span continuous beam model

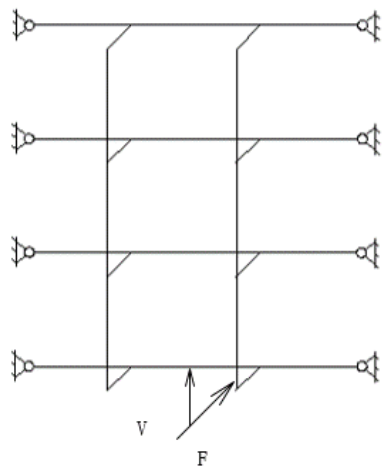

C spatial grid model

Figure 1. Three Simulation Models.

In the simple supported beam model, both ends of the guide are considered to be hinged; both ends of the three-span continuous beam model are considered to be hinged, and the middle two nodes are regarded as rigid contact

\section{Calculation of Mid-Span Deflection of Model}

For the maximum deflection of the simple beam model and the three-span continuous beam model, according to the mechanics of materials and the use of building structure statics to get its formula. In the simply supported beam model, the maximum deflection occurs when the load is applied to the mid-span nodes; in the three-span continuous beam model, the maximum deflection occurs when loads are applied to the three mid-span joints respectively[3].

Equations of the maximum deflection of the simply supported beam model:

$$
w_{\max }=-\frac{l F l^{3}}{48 E I}
$$

Equations of the maximum deflection of the three-span continuous beam model:

$$
w_{\max }=-K \times \frac{F l^{3}}{100 E I}
$$

The meaning of each parameter:

- $\mathrm{F}$ is the force;

- $l$ is the length of the single-layer canal (ie, the distance between the canopy beam layer);

- $E$ is the elastic modulus of the material;

- I is the section moment of inertia;

- $\mathrm{K}$ is the maximum deflection calculation factor obtained by the look-up table.

According to the actual data: 


$$
\begin{gathered}
\mathrm{F}=8000 \mathrm{~N} \\
l=4 \mathrm{~m} \\
\mathrm{E}=2.06 \times 10 \mathrm{MP} \\
I=\frac{B H^{3}-b h^{3}}{12}
\end{gathered}
$$

In the mid-span of the first span and the third span in the three-span continuous beam:

$$
\mathrm{K}=1.458
$$

In the second span.:

$$
\mathrm{K}=1.146
$$

So the following data can be calculated:

The maximum deflection of the simply supported beam model is:

$$
w_{\text {max }}=-1.57 \mathrm{~mm}
$$

The maximum deflection of the three-span continuous beam is:

The mid-span of the first and third span:

The mid-span of the second span:

$$
w_{\text {max }}=-1.12 \mathrm{~mm}
$$

$$
w_{\text {max }}=-0.86 \mathrm{~mm}
$$

However, it is not easy to calculate the deflection of each span in the spatial grid structure. In order to obtain the deflection of the spatial grid structure under the moving load, it is necessary to carry on the finite element simulation analysis.

\section{Finite Element Simulation Analysis}

\subsection{Define Materials}

According to the design data of a mine, both sides of the guide are arranged in parallel. The length of the guide is $12 \mathrm{~m}$, two guides are located $1.8 \mathrm{~m}$ apart, the length of the bunton is $4.86 \mathrm{~m}$, the span of bunton is $4 \mathrm{~m}$, the short beam length of the connecting guide and bunton in the spatial grid model is $0.1 \mathrm{~m}$. Materials are Q235 cold-formed square steel, cross-sectional size of $180 \times 180 \times 10$.

According to the above data beam, the analysis model is established in ANSYS, set the modulus of elasticity for $2.06 \times 10^{5} \mathrm{MP}$, poisson's ratio is 0.3 , the density is $7800 \mathrm{~kg} / \mathrm{m}^{3}$, choose the BEAM188 three-dimensional beam element.

\subsection{Meshing, Applying Constraints and Loads}

The size of the global control element is $0.1 \mathrm{~m}$, and the guide length $12 \mathrm{~m}$ used to apply the load is divided into 120 elements with 121 nodes. For both ends of the hinge point, constrain the X, Y, Z direction of displacement; for the model of spatial grid structure, constrain the UX, UZ, ROTX, ROTY, ROTZ degrees of freedom of the short beam at the junction of the guide and the bunton; constrain the UX, UY, UZ degrees of freedom at both ends of the bunton. The spatial grid structure is shown in Figure 2. In this paper, we use the * DO loop to apply the load to the 121 nodes of the guide in order to simulate the relative motion between the guide and the cage roller by using the method of moving load in the vehicle-bridge analysis model[4-5]. 


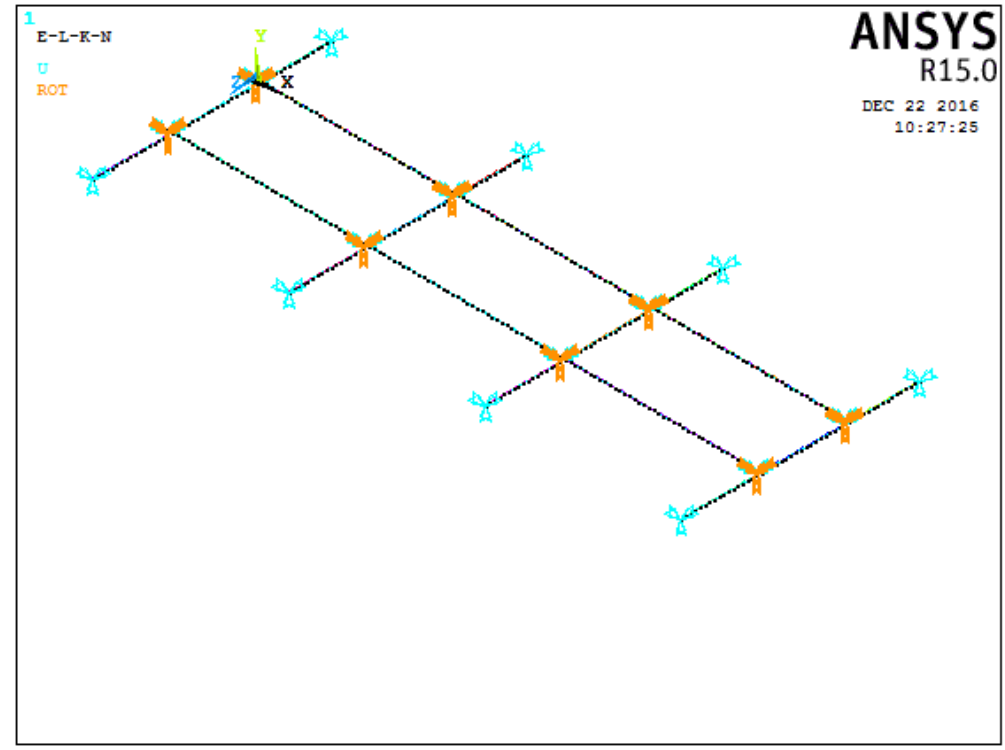

Figure 2. Spatial Grid Structure Model Meshing and Constraints.

According to the data, the pre-tightening force of the $\mathrm{Y}$ direction of the cage roller is $8000 \mathrm{~N}$, the speed of the uniform speed is $8 \mathrm{~m} / \mathrm{s}$. Assuming the uniform speed does not impact on the guide, defining the moving load $\mathrm{P}$ is $8000 \mathrm{~N}$, along the $\mathrm{Y}$ axis negative direction, and the moving speed is $8 \mathrm{~m} / \mathrm{s}$, along the $\mathrm{X}$ axis positive direction.

\subsection{Simulation Results}

The NSOL function is used to extract the displacement value of the Y direction of the simple supported beam, the displacement values of the three mid-span nodes in the Y direction of the threespan continuous beam model and the spatial grid model. Then export the data to MATLAB, take the time as the $\mathrm{X}$ axis, the displacement as the $\mathrm{Y}$ axis, draws the displacement - time curve, as shown in Figure 3

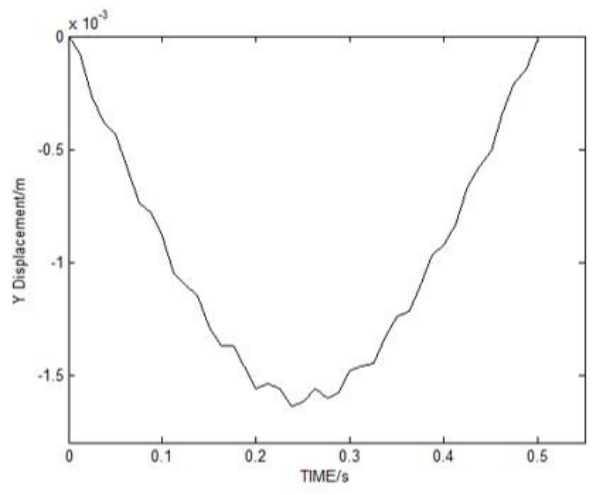

A The Mid-span of simple supported beam

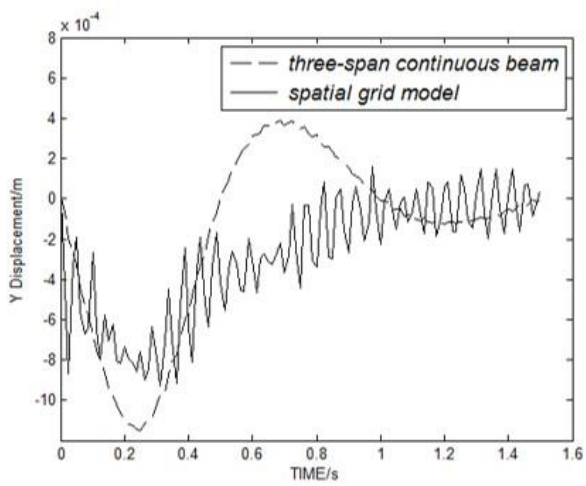

B Displacement of the first mid-span 


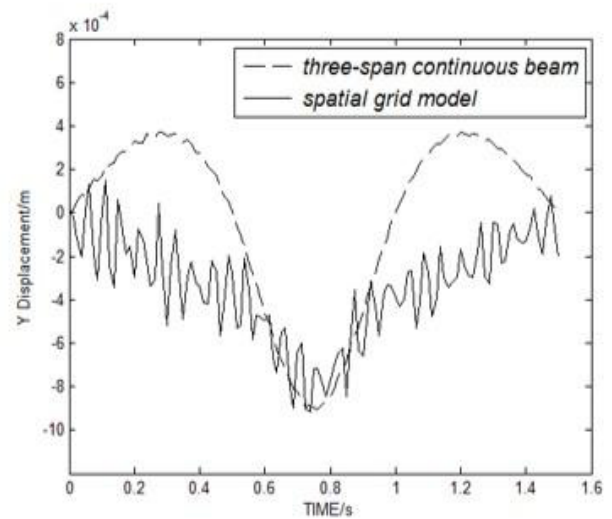

C Displacement of the second mid-span

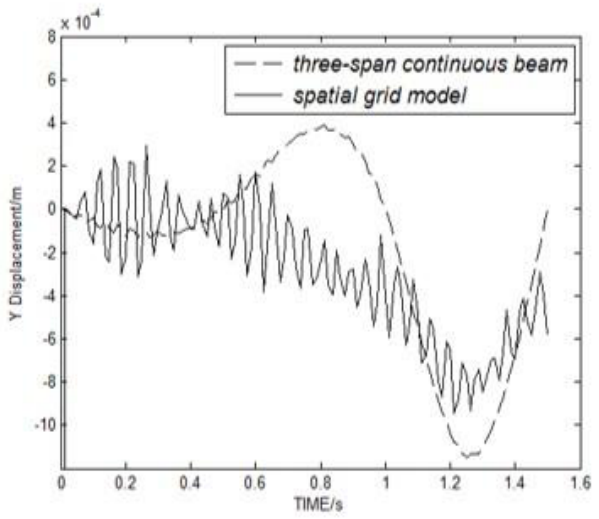

D Displacement of the third mid-span

Figure 3. Comparison of Mid-Span Deflection of Each Model.

\section{Result Analysis}

According to the simulation results, the maximum deflection values in each span of the simply supported beam model, three-span continuous beam model and spatial grid model are shown in Table 1 .

Table 1. Maximum deflection values in each $\operatorname{span}(\mathrm{mm})$.

\begin{tabular}{|c|c|c|c|c|c|c|c|c|c|}
\hline & \multicolumn{3}{|c|}{ First Mid-span } & \multicolumn{3}{c|}{ Second Mid-span } & \multicolumn{3}{c|}{ Third Mid-span } \\
\cline { 2 - 9 } & $\begin{array}{c}\text { Simulat } \\
\text {-ion }\end{array}$ & $\begin{array}{c}\text { Theoret } \\
\text {-ical }\end{array}$ & $\begin{array}{c}\text { Deviati } \\
\text {-on }\end{array}$ & $\begin{array}{c}\text { Simulat } \\
\text {-ion }\end{array}$ & $\begin{array}{c}\text { Theoret } \\
\text {-ical }\end{array}$ & $\begin{array}{c}\text { Deviati } \\
\text {-on }\end{array}$ & $\begin{array}{c}\text { Simulat } \\
\text {-ion }\end{array}$ & $\begin{array}{c}\text { Theoret } \\
\text {-ical }\end{array}$ & $\begin{array}{c}\text { Deviati } \\
\text {-on }\end{array}$ \\
\hline $\begin{array}{c}\text { Simply } \\
\text { Supported } \\
\text { Beam }\end{array}$ & & & & -1.64 & -1.57 & 0.07 & & & \\
\hline $\begin{array}{c}\text { Three-span } \\
\text { Continuous } \\
\text { Beam }\end{array}$ & -1.15 & -1.12 & 0.03 & -0.90 & -0.86 & 0.04 & -1.15 & -1.12 & 0.03 \\
\hline $\begin{array}{c}\text { Spatial Grid } \\
\text { Model }\end{array}$ & -0.93 & & & -0.92 & & & -0.93 & & \\
\hline
\end{tabular}

It can be seen from Table 1 that when the calculation model of guide and bunton is calculated according to the simple supported beam, its mid-span deflection will be much larger than that of threespan continuous span beam and spatial grid model. So it is necessary to increase the cross-sectional area of the guide or the use of higher bending stiffness of the material, thereby increasing costs[6]. At the same time, it can be seen from the table that the maximum deflection of the mid-span of the simple beam model and the three span continuous beam model are basically the same as the theoretical calculation result.

The deflections of the three-span continuous beam model and the spatial grid model are similar at the maximum. However, according to the comparison of mid-span deflection curves, the mid-span deflection of the three-span continuous beam is relatively gentle, but the mid-span deflection of the spatial grid model is more violent, which is bound to produce vibration, impact on the stability of the guide structure 


\section{Conclusion}

- Finite element simulation deviation within the allowable range. So the finite element method can be used to simulate the spatial structure of the guide structure;

- The deflection of the simply supported beam model is much greater than that of the three-span continuous beam and spatial grid model. The maximum deflection in each span is similar to the threespan continuous beam model when calculated by the space grid model;

- Compared with the three-span continuous beam model, when the space grid structure is used, the mid-span deflection of each span is more violent under the moving load. In the design calculation of the tank, to take into account this situation, to avoid fatigue damage.

- Compared with the theoretical calculation, the finite element method is more consistent with the actual working conditions, especially for the analysis of complex moving loads, the use of finite element simulation can provide the necessary reference for the design and calculation.

\section{Acknowledgements}

This research was supported by the Key Project of Natural Science Foundation for Anhui University (No.KJ2015ZD019).

\section{References}

1. Wang Dongquan,Shi Tiansheng,Liu Zhiqiang and Guo Jinpu. Method for Calculating the Structure of Rigid Shaft Equipment of Deep Mine. Journal of China University of Mining\& Technology. 26(1):5 8,(1997)

2. Qin Qiang,QI Xiao-nan,Ding Jian-guo and Jian Hui. Analysis on Shaft Guide Equipment Quality. Coal Mine Machinery .36(6):168-170,(2015).

3. Guo Zhenxi,Zhang Shuyi. Static Caculation Handbook for Practical Strucyure. China Machine Press. 4:320-322,(2009)

4. Ge Junying. Analysis of Bridge Structure Based on ANSYS. China Railway Publishing House. 8:150-156,(2007).

5. SANMANI F S,PELLICANO F. Vibration reduction on beams subiected to moving loads using linear and nonlinear dynamic aborbers[J]. Journal of Sound and Vibration. 325:742 754,(2009)

6. Jiang Yuqiang. Research on Nonlinar Coupling Characteristes and Condition Assessment of Vertical Steel Guide System. China University of Mining and Technology.(2011). 